This is an electronic version of an article published in Gallagher, K., \& Service, I. (2010) Applied theatre at the heart of educational reform: An impact and sustainability analysis. Research in Drama Education:

The Journal of Applied Theatre and Performance, 15(2), 235-253. Cognition and Instruction is available online at: www.tandfonline.com with http://www.tandfonline.com/openurl?genre=article\&issn=1356$9783 \&$ volume $=15 \&$ issue $=2 \&$ spage $=235$

\title{
Applied theatre at the heart of educational reform: An impact and sustainability analysis
}

\author{
Kathleen Gallagher \\ Ivan Service
}




\section{Applied theatre at the heart of educational reform: An impact and sustainability analysis}

\section{Introduction}

In September of 2007, the Elementary Teachers' Federation of Ontario (ETFO), the union representing over 73,000 teachers of children ages 4 through 13 (http://www.etfo.ca), launched a programme to assist educators in addressing the issue of poverty in their schools and surrounding communities. ETFO's project used applied theatre as a tool for teachers' professional development. The play Danny, King of The Basement - written by David Craig and performed by Roseneath Theatre Company ${ }^{1}-$ was presented in fifteen school districts across the province as an educational tool to raise awareness among ETFO's members about issues of poverty. This applied theatre intervention was complemented by professional development workshops for teachers and school grants of $\$ 10,000$. The objectives of this project were:

1. To allow ETFO's members to explore their assumptions about poverty and its impact on students, and to deepen their understanding of the complexities of poverty;

2. To explore how ETFO's members can work together in a school and with their communities to mitigate the effects of poverty on student achievement, and encourage discussion regarding assumptions of the role of family/home life in student achievement.

\footnotetext{
${ }^{1}$ For more information about the play and its Ontario tour see http://www.etfo.ca/AdvocacyandAction/SocialJusticeandEquity/Danny/Documents/Danny\%20King\%20o f\%20the\%20Basement \%20Tour\%20Flyer.pdf
} 
This article examines the central role that applied theatre played in carrying out these objectives. In other words, What could Danny, King of the Basement do? And what did ETFO accomplish from 2007 to $2009^{2}$ in their provincial poverty intervention? What were the roadblocks? What were the victories? In short, what difference, according to its teacher-members, did this comprehensive project make?

\section{ETFO's Poverty and Education Project}

Almost a decade ago, Levin and Riffel (2000) argued that one of the most striking aspects of education reform has been the lack of attention paid to the most important single determinant of education outcomes - socio-economic status of families. Responding to this lacuna, ETFO initiated a province-wide project called the Poverty and Education Project ${ }^{3}$, which sought to improve the social and academic chances of those Ontario students most economically disadvantaged. The Ontario Ministry of Education and the Teachers' Federation together had the vision of addressing the issue of poverty in education in order to improve the academic performance of children from economically disadvantaged backgrounds (McAdie, Giles, Makan, \& Flessa, 2006). Currently, one in six children across Ontario lives in poverty (Campaign 2000,2007) and the statistics indicate serious inequities with respect to the distribution of wealth in the province (see Table 1 below). These inequities are layered with further injustices in terms of gender, race, and immigration status (Canadian Research Institute for the Advancement of Women, 2005; Color of Poverty, 2007; Ontario Ministry of Education, 2006). With significant grants from the Government of Ontario and the Literacy and Numeracy Secretariat, this project sought to take a multifaceted approach to the issue of poverty within Ontario, an approach that could be sustained into the

\footnotetext{
${ }^{2}$ The authors would like to acknowledge Luisa Sotomayor, former research officer at the Centre for Urban Schooling, for her invaluable contributions to the conceptualizing and report writing of the first year of the this study.

${ }^{3}$ The Federation was critiqued for the use of the term "Poverty", some feeling it was potentially too stigmatizing. It was argued, by the Federation, that one of the problems schools face is just such a reluctance to clearly name the issue. The term poverty remained in the title.
} 
future for participating schools (McAdie, Giles, Makan, \& Flessa, 2006). Flessa (2006) identified how the union could structure and give direction to their Poverty and Education Project so that it would build the necessary capacity and culture within schools to take on such a challenging task:

1. Design a programme that has teachers challenge the various assumptions they have of people living in poverty as these stigmas greatly prevent equitable solutions to be identified, and;

2. Allow teachers and schools to develop their own ideas and initiatives, and establish community partnerships to address issues of poverty within their local contexts as opposed to generalized, policy-driven solutions being imposed onto them.

Thus, the purpose of ETFO's Poverty and Education Project was to provide professional development opportunities to the members of the Federation in order to help elementary schools better understand child and family poverty as well as build the capacity to assist students who are economically disadvantaged. Since much of the discourse about poverty, particularly among teachers, tends to focus on what students lack, on the 'deficits' they come to school with, like their lack of access to cultural or arts activities and events often enjoyed by their middle-class peers, we were interested, as researchers, to see how the play, and its surrounding professional development for teachers, might expose or challenge this kind of 'deficit thinking', address stereotypes of poverty through school-wide plans, and help teachers to better see the assets their students bring to the classroom. The ETFO project consisted of providing funding, material and instructional resources, professional development opportunities, and release time to teachers so that they might begin the process of challenging their assumptions and developing their school-based initiatives (see Table 2 below). To support the central component of the theatre intervention, the Federation provided scripts of the play, Danny, King of the Basement and scheduled time with the actors 
after the performance to begin some curricular thinking about how to bring the play into the classroom after its performance and make the story relevant to both teachers and their students. These activities aimed to give further curriculum life to the play after the performance.

Table 1. Statistics on poverty in the province of Ontario, Canada.

- One in six children in Ontario - approximately 478,480 - live in poverty.

- 132,000 children rely on a food bank each month.

- Two in every five children living in low-income families have a parent working full-time, year round.

- Women and youth account for $83 \%$ of Canada's minimum wage workers.

- The majority $-54.6 \%$ - of children living in low-income, single-parent families live with their mother.

- $47 \%$ of children in new immigrant families and $32 \%$ of children in racialized families are considered poor, an increase of $60 \%$ over the last 20 years.

- $70 \%$ of Ontario's Aboriginal population lives off-reserve. One-third of off-reserve Aboriginal children live in poverty.

Information collected from Campaign 2000; Canadian Research Institute for the Advancement of Women, 2005; Color of Poverty, 2007; Ontario Ministry of Education, 2006. 
Table 2. List of resources provided to participating schools in the Poverty and Education Project.

- Performance of the play, Danny, King of the Basement.

- Afternoon workshops with the actors.

- Class scripts for the school (prior to performance date)

- ETFO's community resource poster

- Copies of the DVD, One in Six, which provided information and stories about poverty and education.

- Professional development opportunities.

- $\$ 10,000$ in funding

- 20 teacher release days

\section{Applied Theatre}

In our view, the play was both a surprising and a courageous choice for this project. Surprising in the sense that theatre was being located centrally in a multi-million dollar provincial education initiative and courageous because the narratives of poverty are disturbing and theatre, we maintain, allows for a close examination of narratives. One of the goals of the project was to examine the entrenched views that educators may hold about poverty, such as the notion that people are poor because they have poor work habits or that children affected by poverty lack the qualities and attitudes necessary for achieving success, which can and will be fixed through schooling (Flessa, 2006). Explanations of poverty such as these that focus on what students lack are historical in nature, stemming from various public policies related to 
poverty, like those that emerged during the Great Depression and War on Poverty (Katz, 1993 \& 1995 in Flessa, 2006). Deconstructing or challenging such narratives was something theatre work might be able to accomplish. Danny, King of the Basement offered what one might call a counter-narrative to some of the ubiquitous stories about what it means to live in poverty. In this case, the 'typical' narrative of poverty was re-imagined as a story of resilience, imagination, and community. Danny, a pre-adolescent boy, found great strength in his plight and used his imagination to challenge many of the barriers (educational and otherwise) that he faced as a result of his economic disadvantages. It is a play that moves, in some ways, between realism and surrealism. It uses a large abstract set, transforming space in cartoon-like fashion. The dialogue of the script vacillates between a linear narrative and a fantastical adventure. In a scene between Danny and his mother, Louise, we hear the pragmatism of Danny's life set against his imaginative, escapist impulses:

Danny: We'll get kicked out.

Louise: No we won't.

Danny: We always do when you keep the money.

Louise: Not always.

Danny: So where is it? (beat) Show me.

Louise: Okay, I spent it.

Danny: See.

Louise: But I spent it on you.

Danny: It's always the same.

Louise: On boots. You need some new boots.

Danny: My boots are fine.

Louise: They're too big. Look. These are just your size. 
Danny: Take them back.

Louise: I can't.

Danny: Why not?

Louise: They were on sale.

Danny: Stupid, stupid, stupid, stupid-

Louise: Danny, calm down.

Danny: That's okay. I like moving.

Louise: Danny...

Danny: I'm the king of moving.

(pages 43-45)

The very real hardships of children living in poverty, attending schools all across the province, were articulated anew and examined by teachers and students, as theatre became a way to communicate differently about familiar hardships and academic challenges. The play's script might well be critiqued for its resilience narrative and potential minimizing of the actual hardships faced by economically disadvantaged families. Part of how the larger project attempted to avoid this problem was through the teachers' study guide, designed by drama educators. This resource draws on process drama techniques, such as character letter writing, to open up a dialogue about the depictions of poverty prevalent in the play, or whole group role-play as an anti-poverty organization running a fund-raising campaign. Other activities, like preparing a budget to live on with limited funds, invite students and teachers to also think pragmatically about issues of poverty. The post-performance discussions and activities, therefore, largely aim to deconstruct the images of poverty we see in the play and invite students and teachers to engage critically with them. 
The stories we share, through theatre and in life, can be read and interpreted in many different ways; they are always a product of social and cultural experience. Children bring a vast range of stories to the classroom, drawing on their cultural and experiential knowledge, cultures of home, of family, of peers. When these stories are difficult, when they express what students are lacking, such as basic needs that are not being met, teachers enter into difficult ethical terrain, as they make decisions about how to keep their students safe and protect them from becoming stigmatized by the stories of their lives. It is an ongoing challenge for teachers to recognize poverty, to understand the challenges of their students, without further stigmatizing them by drawing attention to difficult circumstances and the issues that arise from them.

I have argued elsewhere that the distinctive force of theatre, however,- its dialectics- invites us to take up points of intersection and confrontation, so that our dramatic explorations do not simply calcify cultural and ethnic boundaries. Instead, theatre opens up a capacity to maneuver across borders and develop capacities for functioning in diverse situations (in Gallagher and Booth, 2003). These are leaps of imagination, not concrete skills or causal relationships. Theatre does not necessarily make us better at understanding the worlds of others, but it does have an uncanny way of making us see both commonalities and differences, to dis/identify in tangible, often affective and visceral ways. In part, Danny, King of the Basement, became a platform for not only the sharing of personal stories but also for opening up teachers' and students' capacities to understand situations vastly different from their own. In the data, we heard, repeatedly, that seeing a live production made possible conversations that would not otherwise have happened. The distance of the stage created a forum for dialogue.

Increasingly, teachers are making decisions about how to positively affect their students' lives beyond the walls of the classroom. Our findings will also illustrate, therefore, how teachers came together to think about the whole student, not just the one in their classroom, and how they created projects to address their students' socio-economic and academic needs. Both inside and outside the classroom, 
Danny, King of the Basement- and how it was used by school communities- became, in the best cases, a kind of lightening rod for a school's ability to see students in their wider social milieux and for teachers' capacity to have difficult but necessary conversations with their students, and again, in the best cases, to hear these stories in new ways. Walter Benjamin (1992) argued persuasively that stories do not provide information or recount events, but more significantly encourage people to share their experiences and stimulate moral discussion. When we are talking about children living in poverty in the so-called developed world, the political, social, and academic story of this poverty must also be grounded in the moral one: it is unconscionable that students in Ontario- one in six- continue to live in poverty.

\section{Research Goals}

The research happened over a two year period. From 2007-2009, through a combination of focus groups, individual interviews, a survey, and case-studies, we sought to describe, from the teachers' perspectives, how the play, Danny, King of the Basement, was received and incorporated into instructional activities and school-based initiatives. We also examined how it contributed to changes in school culture and dynamics, a measure of its potential sustainability over time. Finally, we examined the challenges surrounding the intervention in the hopes that our research would inform future large-scale educational interventions. Our research goals were as follows:

\section{Year 1:}

- To understand agency within constraint ${ }^{4}$.

\footnotetext{
${ }^{4}$ It seemed important, as researchers, to explicitly acknowledge the limited role that a play, or any other form of artistic intervention, might play in the actual lives of economically marginalized children. Rather than anticipating great transformations, we sought to view this project as a way to identify small moments of agency in a context of considerable constraint.
} 
- To examine the role played by theatre to affect change in relationships, initiate dialogue, and deepen understanding of social issues.

Year 2:

- To understand sustainability of the project as a whole, and the applied theatre intervention in particular, for schools with different levels of funding, support, and length of involvement in the overall programme.

\section{Methods}

In each of the two years, 15 elementary schools (the "Danny Schools") from all regions of Ontario were asked to participate in the Poverty and Education Project. These schools were identified as having a large number of students from economically disadvantaged backgrounds and low scores on province-wide academic achievement tests. In Year 1 (Fall 2007 to Spring 2008), 8 of the 15 schools participated in a mixed methods impact assessment, which included focus groups with educators, administrators, and support staff in the fall and spring, interviews with administrators, an online survey in the winter distributed through SurveyMonkey, and analysis of school documents and reports related to their schoolbased initiatives as well as researcher field notes, observations, and photographs. Our chosen sample aimed to represent the great diversity of schools within Ontario (e.g. rural/urban, growing/decaying population size). In Year 2 (Fall 2008 to Spring 2009), a total of 3 schools participated in the case study sustainability assessment. Two of these schools had participated in the Poverty and Education Project during the previous academic year, but only one was continuing to receive financial and material support from ETFO; the third was new to the project and also received the financial and material support from ETFO), The case studies included two focus groups with educators, administrators, and support staff in the fall and spring for the two funded schools while the non-funded school completed a single focus group 
in the winter with many participants submitting their responses to our questions electronically. Schools also submitted various reports and documents related to the project to support our analysis and researcher field notes, observations, and photographs were also analysed. All qualitative data was analyzed using Atlas TI software (2007), which is a virtual workbench for managing the coding of transcripts, photographs, and other similar data. The quantitative data from Year 1 of the study was analysed and processed using SPSS software. Participation in our study was completely voluntary and did not determine whether schools received funding and resources. Teachers, administrators, and school staff had the option of participating in focus group sessions, individual interviews, an online survey, and providing classroom exemplars, documents, and photographs.

\section{Findings: Applied Theatre-Changing School Culture}

The following findings on the role that applied theatre played in changing school culture are primarily from Year 1 of the study, as assessment of the impact of applied theatre was central to our research goals at that time ${ }^{5}$. Various themes emerged that provided insight into the responses of the teachers and students to the play, Danny King of The Basement, and to the theatre workshops that accompanied the play and the teaching methods adopted as a result of the play. We grouped these responses into the following themes: aesthetic engagement; catharsis and empathy; dialogue; change in social relations (among the staff, students, or community); learning from the drama; and drama as a pedagogical tool.

\section{1) Aesthetic Engagement}

\footnotetext{
${ }^{5}$ Other findings from the first year pertaining to the locally-determined school-based initiatives and the leadership styles in each school are beyond the scope of this paper.
} 
Really listening, really thinking about it. I know it's had an impact well beyond that week. We're still hearing things about it. Talking to other teachers too, um, I know that in Mr. Adam's room upstairs he has kids that are making text connections to it, and still talking about it. So it's really carrying on, and affecting all the kids in the school.

Our theme of aesthetic engagement refers to any responses describing the intrinsic value of the theatre event. Overall, the staff at each of the schools found the play to be an enjoyable experience. The play was important for energizing the staff and students to take on the topic of poverty, despite the perceived challenges that they face. The teachers reported that attending the performance had much greater meaning for the students than just finding it to be a "fabulous" or "wonderful" experience.

The experience of attending a drama was very new to many of the students, particularly those in remote (Northern) or rural areas of Ontario; nonetheless, they responded positively to the performance. Teachers reported that their students really "connected" with the drama as they continued to speak about it months after the performance at their school. Among the teachers, there was a general sense that attending a live performance leads to some form of reflection within the students that involves connecting the material or messages of the drama with the experiences or realities of their own lives:

So it gives them time to sit there and enjoy the show, enjoy the music, but also to reflect upon what they did or their own potential. Drama is extremely helpful. So, for that reason the drama got our kids thinking about their own actions, their own human nature.

2) Catharsis and Empathy

Well, particularly a scene where Danny is being revived after he has been exposed to the elements and the kids in three groups that made the comment... about the fact that it was fairly awful how he 
found himself in that...So the kids talked about options and things within the community that were available to people in need...

So far, this project has given my students a sense of enjoyment in an activity that is completely foreign to them and shown them that they are not alone in their feelings. It even brought one of my students to tears.

These two responses- cathartic and empathic- are clearly different. In the data, however, they most often appeared together. We thought this significant and so grouped these themes together. Any responses that described an emotional response to the play or some shift in understanding or thinking as a direct result of watching the performance were grouped under the theme of catharsis. This does not necessarily mean that there was some form of emotional purging involved; it could simply mean that the play evoked feelings, emotions or thoughts articulated by teachers or students. Empathy, on the other hand, refers to a sense that the teachers and students were able to understand another person's position, such as the characters in the play, while watching the play. It also included an increase in empathy towards members of the schoolcommunity as a result of watching the play. For the teachers, the emotional and cognitive responses to the play were similar across schools; they agreed that it prompted a great deal of reflection:

There is now a greater amount of patience for the students on the part of some teachers as a result of the play...The sentiment was that the play inspired one to remember why one wanted to teach in first place, something that can get lost in the daily grind of school life.

The content and the message of the play were very evocative for the majority of students and teachers. The play often led teachers to reflect on their own assumptions about the challenges faced by the students in their school: 
It prompted conversation among the staff and students, prompted staff to examine how to enable students to live through impoverished stereotypes, and to have a more nuanced perspective about the complexities of poverty.

The teachers felt that the students were also able to connect with the play and benefit from it because they were able to connect with the characters directly or with the "cultural symbols" of the play. This last point was of particular interest to us because the play was situated in Toronto, a densely populated urban centre, unlike the communities of many of the "Danny Schools". Despite the fact that the setting of the story was in Toronto, students were still able to relate to the implicit or underlying themes of the play. Potentially, these themes have a quality that is "universal", teachers argued, (or at least symbols that are shared throughout North American culture) and allowed for students from surrounding areas of Toronto or even in rural or Northern parts of Ontario to connect with the story.

\section{3) Dialogue}

...before the play came to the school we were asked to discuss poverty... and I found my students didn't really understand the word poverty...but it was after the play came to the school that the conversation became really interesting...I had kids who were twelve years old understanding the parent's perspective, understanding the parent's motivations, understanding the parent's challenges, which I didn't think they were capable of doing.

The nature of the discussions that followed the performance became an important theme in our analysis. The responses were grouped into those that refer to the frequency of discussions about poverty that followed the performance as well as the quality and depth of the conversation between teachers and 
students. For the majority of schools, discussions about the drama and its relevant themes continued well beyond the date of the performance.

Teachers said that they were exploring topics with students that they had not previously talked about. Students were openly raising issues that were important and relevant to their school-community and questions were being posed that were never addressed prior to the performance, many teachers reported:

In the classroom I've noticed it opened up a lot of awareness. They talk about it more amongst each other and if we're having a group discussion they'll mention poverty as an issue more frequently than they ever did before.

The question we became interested in, then, was whether such discussions led to a deeper understanding of the structural issues that produce or maintain poverty within their community or globally. This was more difficult to determine from the data we had.

What we could clearly see in the data, however, was how these discussions extended the teachers' and students' understanding of poverty. Students were clearly able to connect the various elements of the play with their own knowledge and experiences. In other words, they were challenging what they had previously understood poverty to mean:

... seeing Danny set a stage to discuss poverty and the multitudes of poverty in a different aspect. Whereas instead of saying someone, you know, it might be like first they can relate, well, Danny in the play he was poor, like, monetarily, but, you know, he was rich in his imagination and stuff like that. So, they can talk about, you know, the characteristics of different types of poverty of the stage characters.

The responses really give the impression that in order for this growth in understanding to occur, it was critical for teachers and students to see the play, see a representation of people who live in poverty, to 
really discuss the topic in depth. Finally, teachers often concluded, the play provided a "safe", (we understood this to mean distanced) forum for meaningful discussions to occur.

In other words, without the opportunity to reference the play, teachers would have been more reticent to address the issue of poverty head on because it clearly affects many of their students personally. Likewise, students may not have been comfortable engaging in dialogue about poverty had they not had someone else's (Danny's) narrative to examine.

4) Changes in Social Relations

After seeing 'Danny King of The Basement' and the readings...it really opened the doors to free communication.

Ifeel the whole project has brought the staff together...

Amazing staff, ideas and programs really came out easily and staff worked hard to figure out how to put it all together

Any time a response indicated that a new connection emerged within the school or that the social relations were changed due to the dialogue that was provoked from watching the play, it was coded within this theme. These kinds of responses usually referenced relationships between teachers and students or between teachers themselves. For instance, some spoke of the conversation that was provoked by the play and how it provided them with a sense of belonging to a collective of professionals that could "make a difference" for kids.

When it came to change among the teachers' and administrators' relationships, there were fewer responses. For at least one school, though, having the trust and support of the administrator may have 
validated the steps teachers were taking to assist their students. But it was clearly the relationship between teachers and students that was most strongly impacted by the drama.

In my classroom, I have a lot of students that act out because they're hungry, and that they haven't had proper nutrition, and I have this one student in particular that, um, it's really severe. And this year, because of the inclusive environment that we've created, and through talking about poverty, he will no longer shut that off, he will say out loud, put his hand up, and when we're on the carpet and say, "You know Miss Betty I'm really hungry, can I have a banana?...That's something that they feel like they can discuss not only one on one but they feel like they can discuss it with their peers, so, it's pretty good.

There is a real sense that the drama allowed for a very honest, open dialogue to begin between the teachers and students. No longer were children concealing the actual issues they are facing (e.g. hunger, ripped clothing, no pencil); instead they began treating these issues as legitimate sources of concern within an educational setting.

5) Learning from the drama

It brought personal beliefs and experiences to the forefront through character experiences and situations. This play was excellent and helped me get in touch with what some of our students are likely feeling, and why they are reacting the way they do.

For us, it's broadened our definition because we often think of poverty we only think in terms of physical needs but --you see there are some kids that are emotionally poor that are well provided for but...the comments that they make, you know give the impression that they are emotionally poor... 
Another strong theme that emerged was that teachers and students were learning about issues related to poverty directly from watching the play. Responses by the teachers at the various schools suggest that they, and their students, had been challenged to change certain strongly held ideas about poverty or to expand their thinking about how poverty manifests itself. There was even some evidence to suggest that this new understanding of the "realities of poverty" helped teachers to recognize poverty within their own school-communities where they had not before seen it. Again, the play as a 'representation' of local and personal issues allowed for new learning to occur and for learning to occur through analogy. Long ago Dorothy Heathcote spoke of the simple power of this way of working:

Dramatizing makes it possible to isolate an event or to compare one event to another, to look at events that have happened to other people in other places and times perhaps, or to look at one's own experience after the event, within the safety of knowing that just at this moment it is not really happening (Heathcote 1975 in Johnson and O’Neill, 1984, p.90).

6) Pedagogical tool

We have addressed the issue numerous times in the classroom. It is also a good thing to refer back to. There were interesting Drama activities that we did in extension. Language activities are ongoing.

When we're reading books, poverty books, they still do refer back to "Danny", as a way to build a scaffolding, to build a connection 
And I was impressed with how fast they picked up drama as a means of communication. They respected the form of communication...it moved us ahead in conversation to a deeper depth, discussing everything in language arts...So I felt that it had spin offs that were valuable in the curriculum content as well.

I teach visual arts and drama to the intermediate students and we are currently using the script in the basement for group work and it has certainly generated interesting conversation and a very poignant and attainable message to kids at this level... it is a very useful and a wonderful tool to use in class.

The final theme that emerged was incorporating themes or ideas found within the play into teaching practices and classroom activities. As these responses demonstrate, teachers felt that the drama provided a way to address issues of poverty with their students, created the opportunity for new or different lessons, or for introducing drama as an art form into the classroom. As was evident in many responses, it was beneficial to reference the drama itself in order to make the lesson relevant, meaningful, or even "more concrete" for students.

Overall, there is an indication that the experience of drama, both seeing it and participating in it, had a direct impact on the way teachers constructed lessons and the material that they covered. It also provided a concrete reference point for teachers to connect the lessons with and even, for many, introduced theatre as a new way of communicating. 


\section{Themes Beyond the Applied Theatre Intervention}

Many themes emerged from our data that were beyond the scope of the applied theatre intervention such as: Principals’ Awareness; Teachers’ Awareness; Teachers’ Practice; Collaboration; Engagement; Leadership; Impact on Students; School Environment; School Culture; Project Operations

We cannot pursue these here but make note of them to suggest that the themes that emerged concerning the applied theatre intervention were a part of a network of other thematic findings that helped to create a broad picture of the impact of the overall poverty and education project. It is important to note that no change occurred as a result of any single factor. Instead, as may well be expected, these factors interacted on various levels and at different points during the project to influence the progress of the school-based initiatives and the overall professional development of the teachers.

\section{Findings: Sustainability of Applied Theatre}

The following summary of findings has to do with the sustainability of applied theatre from one academic year to the next. In many cases schools were only supported by ETFO for one year. Schools had to therefore consider how to fund and manage their initiatives into the following year while also managing various other programmes targeted at 'disadvantaged schools' that were occurring simultaneously.

For our three case studies, the focus on the Danny play as a means of organizing the school-based initiatives seemed to be lost:

Well they only know about swimming, but we haven't really tied it to the Danny project or Danny play or project with the kids.

Last year the focus for us was really on Character Education... we have veered off in a different direction while keeping going what we did last year. 
It was interesting that for each of the schools, Danny as a reference point for launching the initiatives and generating discussions had become less obvious, if it was used at all. Even though it had served such an important role during Year 1 of the project, schools either: (a) found other themes or ideas to focus their school-based initiatives or (b) continued with the spirit of the play, but made few if any references to it during Year 2. Despite the apparent loss of an explicit reference to the Danny play, the core changes to the culture of the school persisted. And these core sets of values that the schools had adopted were still influencing how they thought about their pedagogical practices, their awareness of the challenges that their students face as a result of poverty, and even the development of a critical lens towards existing school programmes that may be excluding the students and families of their school who are economically disadvantaged:

I'm an awful lot more sensitive, I think most teachers are to where our kids are coming from and it affects their work in school and so on. And I just have a class full of needy kids this year. And I probably always have had a class of needy kids, I just didn't really pay much attention to the need. Or not enough attention. I mean you're always aware of the neediest, but you don't realize that seventy or eighty percent of them would live under the definition of poverty. They just would.

Although it was a project revolving around the play 'Danny, King of the Basement' our staff was able to personalize it to the community. In doing so, the interest and commitment to carry on has been good... Well I'm much more attentive to parents and to kids. I'm listening a lot more than I used to. So, you know the teacher-learner relationships are just a whole lot better. So make time for that to happen and good things happen. 
In Year 1, the play was clearly a powerful catalyst for difficult discussions between teachers and students; it also became a shared reference point for keeping alive such conversations about students' (educational) needs. We noted, in Year 2, how much the 'live theatre' intervention receded into the background in schools that did not embed the arts into their school initiatives compared to those that did. This outlines the very clear difference between the arts as a 'one off' event, however successful, and the arts as central to a programme initiative, with the latter promoting discussion and raising issues in an ongoing way that are relevant to students' lives. At one of our schools, in the second year of the project, the arts (music, drama, visual) became the proxy for 'community'. Teachers embedding the arts or other social interest programmes such as sports, house leagues, crafts, hair salons into their in-class and out-ofclass time with students revealed talents and abilities of students that had previously been untapped:

I don't think we've seen our kids as talented and it's kind of -we don't see their art around the school or we didn't see their art around the school and we didn't know that some kids could sing and had beautiful voices. And maybe that's our own, you know, our problem that we weren't looking for it. But definitely when we're teaching each other to be looking for those things we're seeing them and we're finding the talent and we're-we call it cultivating the talent. And we're really...encouraging it. So for me it's definitely a new focus.

This approach built community and encouraged "positive behaviours" from students, and had important impact on the whole school. Resources were, naturally, key to this kind of development. Continuing resources allowed one school to build upon the arts as an important mode of communication between staff and students throughout the school.

What is important here is that making a strong community in a diverse school cannot rely upon some recovery of a more homogenous past, but of finding new strengths in the differences that can be 
harnessed to enrich social cohesion rather than challenge it. The arts are not a panacea, to be sure, but the arts do help schools create community through modest daily practices.

Nicholson (2005) argues effectively that applied theatre enables people to move beyond the ordinary and everyday, and use the aesthetics of drama, theatre and performance to gain new insights into the social and cultural practices of life. She writes:

Creative spaces are those in which people feel safe enough to take risks and to allow themselves and others to experience vulnerability. It is creative moments of transition that enable participants to move out of restricted spaces- literally or symbolically- and beyond identities that are fixed and codified by particular spatial practices into new forms of social identification (p. 129).

Every aspect of her observation resonates with our study's findings. Teachers spoke of avoiding the subject of poverty altogether before they had the opportunity to engage in dialogue with their students about the shared experience of seeing the play. Discussions about the play became the 'meeting place' for conversations about vulnerability. In naming these vulnerabilities, students challenged the fixities of 'deficit identities', and through processes of identifying with or critiquing the play's characters and experiences, shed new light on familiar problems and worries, and cast themselves in potentially new social roles.

\section{Conclusions}

From our analysis, it was clear to us that the applied theatre intervention positively affected pedagogical relationships and acted as a catalyst in exploring new pathways to teaching and learning in communities experiencing the greatest obstacles to academic success and social well-being. Applied theatre proved particularly effective in initiating dialogue and transforming social relations. Flexibility was key to programme success and the subsequent workshops, grants, release days, and efforts to embed the learning 
in the curriculum raised general consciousness and kept the themes of the play alive, if not the details of the play itself.

The fictional narratives of the play had an impact on the narratives of self-hood that students began to express. This, in turn, changed the terms of communication and engagement between teachers and students. These changes in relationships clearly affected the culture of the school. And when these improved social relations were harnessed to whole school projects and curriculum extensions, the impact of the play and its messages about poverty was effectively multiplied. 


\section{References}

Benjamin, W. (1992). The Storyteller. Illuminations, trans. H. Zohn. London: Fontana Collins. pp. 83107.

Campaign 2000 (2009) 2008 National Report Card On Child and Family Poverty in Canada. Retrieved on August 19, 2009. http://www.campaign2000.ca/rc/

index.html

Campaign 2000 (2007). Child poverty in Ontario: Promises to keep...2006 report card on child poverty in Ontario. Retrieved on August 19, 2009. http://www.campaign 2000.ca/rc/prov.html\#ON

Creswell, J. W. (2003). Research design: Qualitative, quantitative, and mixed methods approaches. Thousand Oaks, CA: Sage Publications, Inc.

Connell, R. W. (1994). Poverty and Education. Harvard Educational Review, 64(2), 125-149.

Flessa, J. Poverty and Education Literature Review. ETFO, December 2006. p.37

Gallagher, K. (2003). Emergent Conceptions in Theatre Pedagogy and Production. In K.Gallagher and D. Booth (eds.) How Theatre Educates: Convergences and Counterpoints with Artists, Scholars, and Advocates. Toronto, Buffalo, London: University of Toronto Press.

Johnson, L. and C. O’Neill (1984). Collected Writings on Education and Drama. Evanston, Illinois: Northwestern University Press.

McAdie, P., Giles, J., Makan, K., \& Flessa, J. (2006). ETFO Poverty Project. Retrieved on August 19, 2009. http://www.ctf-fce.ca/e/programs/pd/Children_and_Poverty /index.asp

Muhr, T. (2008). Atlas TI (Version 5.2) [computer software]. Berlin, Germany: Atlast.ti Scientific Software Development GmbH. 
Nicholson, H. 2005. Applied drama: the gift of theatre. Houndmills, Basingstoke, Hampshire; New York: Palgrave Macmillan.

Stake, R. E. (1995). The art of case study research. Thousand Oaks, CA: Sage.

Surveymonkey.com (2007). Survey Monkey [Software]. Available from: http://www.surveymonkey.com 